\title{
Hemodynamic effects of extended prone position sessions in ARDS
}

Martin Ruste ${ }^{1}$, Laurent Bitker ${ }^{1,4}$, Hodane Yonis $^{1}$, Zakaria Riad ${ }^{1,2}$, Aurore Louf-Durier ${ }^{1}$, Floriane Lissonde ${ }^{1}$, Sophie Perinel-Ragey ${ }^{1,2}$, Claude Guerin ${ }^{1,2,3}$ and Jean-Christophe Richard ${ }^{1,2,4^{*}}$ (D)

\begin{abstract}
Background: Hemodynamic response to prone position (PP) has never been studied in a large series of patients with acute respiratory distress syndrome (ARDS). The primary aim of this study was to estimate the rate of PP sessions associated with cardiac index improvement. Secondary objective was to describe hemodynamic response to PP and during the shift from PP to supine position.

Methods: The study was a single-center retrospective observational study, performed on ARDS patients, undergoing at least one PP session under monitoring by transpulmonary thermodilution. PP sessions performed more than 10 days after ARDS onset, or with any missing cardiac index measurements before $\left(T_{1}\right)$, at the end $\left(T_{3}\right)$, and after the PP session $\left(\mathrm{T}_{4}\right)$ were excluded. Changes in hemodynamic parameters during PP were tested after statistical adjustment for volume of fluid challenges, vasopressor and dobutamine dose at each time point to take into account therapeutic changes during PP sessions.
\end{abstract}

Results: In total, 107 patients fulfilled the inclusion criteria, totalizing 197 PP sessions. Changes in cardiac index between $T_{1}$ and $T_{2}$ (early response to PP) and between $T_{1}$ and $T_{3}$ (late response to PP) were significantly correlated $\left(R^{2}=0.42, p<0.001\right)$ with a concordance rate amounting to $85 \%$. Cardiac index increased significantly between $\mathrm{T}_{1}$ and $\mathrm{T}_{3}$ in 49 sessions (25\% [95\% confidence interval $\left(\mathrm{Cl}_{95 \%}\right)$ 18-32\%]), decreased significantly in $46\left(23 \%\right.$ [Cl $\left.{ }_{95 \%} 16-31 \%\right]$ ), and remained stable in 102 (52\% [Cl $95 \%$ 45-59\%]). Global end-diastolic volume index (GEDVI) increased slightly but significantly from $719 \pm 193 \mathrm{~mL} \mathrm{~m}{ }^{-2}$ at $\mathrm{T}_{1}$ to $757 \pm 209 \mathrm{~mL} \mathrm{~m}^{-2}$ at $\mathrm{T}_{3}$ and returned to baseline values at $\mathrm{T}_{4}$. Cardiac index and oxygen delivery decreased slightly but significantly from $T_{3}$ to $T_{4}$, without detectable increase in lactate level. Patients who increased their cardiac index during PP had significantly lower Cl, GEDVI, global ejection fraction at $T_{1}$, and received significantly more fluids than patients who did not.

Conclusion: PP is associated with an increase in cardiac index in 18\% to 32\% of all PP sessions and a sustained increase in GEDVI reversible after return to supine position. Return from prone to supine position is associated with a slight hemodynamic impairment.

Keywords: Acute respiratory distress syndrome, Cardiac output, Prone position, Positive end-expiratory pressure, Transpulmonary thermodilution, Cardiac preload

\footnotetext{
*Correspondence: j-christophe.richard@chu-lyon.fr

1 Service de Réanimation Médicale, Hôpital De La Croix Rousse, Hospices

Civils de Lyon, 103 Grande Rue de la Croix Rousse, 69004 Lyon, France

Full list of author information is available at the end of the article
} 


\section{Background}

Prone position (PP) sessions of at least $16 \mathrm{~h}$ are now an established treatment in acute respiratory distress syndrome (ARDS) patients with $\mathrm{PaO}_{2} / \mathrm{FIO}_{2}$ ratio below $150 \mathrm{mmHg}$, with a clear beneficial effect on mortality $[1,2]$. However, PP impact on hemodynamics has only been ascertained in small studies [3-11], most of which have been performed before the era of protective ventilation and with shorter PP sessions.

While virtually all these studies failed to identify any impact of PP on cardiac index (CI), two recent studies $[12,13]$ have identified a positive hemodynamic effect of PP in two clinical scenarios. First, PP may improve $\mathrm{CI}$ in patients presenting with acute cor pulmonale $(\mathrm{ACP})$, in relation to the unloading of the right ventricle [12]. Second, PP may also improve venous return and subsequently cardiac preload within 20 min after postural change, hence increasing $\mathrm{CI}$ in patients presenting preload responsiveness [13]. However, the persistence of this effect during prolonged PP sessions remains to date unknown. Since prevalence of ACP has been ascertained to $22 \%$ in a large series of 752 ARDS patients [14] and preload responsiveness before PP was identified in $50 \%$ of the patients [13], CI should increase with PP in a substantial fraction of ARDS patients, in conflict with previous reports.

Furthermore, if the shift from supine position (SP) to PP indeed increases $C I$ by increasing venous return, we hypothesize that the shift from PP to SP may have an opposite effect, which remains unreported by previous studies $[3,4,6,7,9,11]$, although strongly underpowered to detect such an effect.

To our knowledge, hemodynamic response to prolonged PP sessions has never been studied in a large series of ARDS patients.

\section{Methods}

\section{Study aim}

The primary aim of the study was to estimate the rate of PP sessions associated with an improvement in CI. Secondary objective was to describe hemodynamic response before, during, and after a PP session.

\section{Study design}

This single-center retrospective observational study reports data from patients hospitalized between July 2012 and December 2016 in an academic medical intensive care unit (ICU). The study protocol was approved by an Ethics Committee (CPP Sud-Est II, IRB 9118), which waived the requirement for informed consent.

\section{Patients}

To be eligible, the subjects had to fulfill all the following inclusion criteria: ARDS according to the Berlin definition [15], application of at least one PP session, and hemodynamic monitoring by the $\mathrm{PiCCO}^{\circledR}$ device (Pulsion Medical Systems, Feldkirchen, Germany). Noninclusion criteria were the following: age $<18$ years, advanced directives to withhold or withdraw life-sustaining treatment initiated before PP session, and previous inclusion during prior ICU admission. PP sessions performed more than 10 days after ARDS onset, or performed during extracorporeal membrane oxygenation, or during which decision to withhold or withdraw lifesustaining treatment was taken, or with any missing $\mathrm{CI}$ measurements before, at the end, or after the PP session were excluded. Multiple PP sessions per patient during the same ICU stay could be analyzed should the eligibility criteria be fulfilled during sessions.

\section{Protocol description}

Since 2011, ARDS management is routinely performed in our ICU according to the protocol used in the PROSEVA study [1] as follows: protective ventilation with a tidal volume of $6 \mathrm{~mL} \mathrm{~kg}{ }^{-1}$ predicted body weight, positive end-expiratory pressure (PEEP) setting using a PEEP$\mathrm{FiO}_{2}$ table [16], administration of neuromuscular blocking agent during $48 \mathrm{~h}$ if $\mathrm{PaO}_{2} / \mathrm{FiO}_{2}<150 \mathrm{mmHg}$ [17], and daily PP during at least $16 \mathrm{~h}$ until achievement of a $\mathrm{PaO}_{2} / \mathrm{FiO}_{2} \geq 150 \mathrm{mmHg}$ with a PEEP $\leq 10 \mathrm{~cm} \mathrm{H}_{2} \mathrm{O}$ and a $\mathrm{FiO}_{2} \leq 60 \%$ in the SP. Hemodynamic monitoring, using the $\mathrm{PiCCO}^{\circledR}$ device, is routinely used whenever severe shock is associated with ARDS [18].

$\mathrm{PiCCO}^{\circledR}$ monitoring was performed using a femoral arterial catheter, connected to an Intellivue MP40 monitor (Philips Healthcare, Andover, MA, USA) equipped with the $\mathrm{PiCCO}^{\circledR}$ module. $\mathrm{PiCCO}^{\circledR}$ calibrations were performed in SP or PP with a horizontal bed position at least every $4 \mathrm{~h}$, with a triplicate intravenous injection of $15 \mathrm{~mL}$ cold $9 \%$ sodium chloride $[19,20]$ through a venous catheter in the superior vena cava territory.

$\mathrm{T}_{1}, \mathrm{~T}_{2}, \mathrm{~T}_{3}$, and $\mathrm{T}_{4}$ were, respectively, defined as the times of $\mathrm{PiCCO}^{\circledR}$ calibration performed in the SP closest to PP onset, during PP closest to session onset, during PP closest to session ending, and after PP.

\section{Data collection}

The following variables were recorded at ICU admission or ARDS onset: demographic data, SAPS II score [21], ARDS severity [15], and risk factors. Occurrence of ACP on echocardiography was recorded at ICU admission and during follow-up in all patients and defined by the association of septal dyskinesia and right ventricle 
dilation (surface ratio of right ventricle over left ventricle greater than 0.6) [14] at any time. The following variables were recorded on the day of each PP session: SOFA score [22], time from ICU admission to PP session, cumulative fluid balance at PP session onset and during PP session, and ARDS adjunctive therapies. Hemodynamic variables were recorded at $T_{1}, T_{2}, T_{3}$, and $T_{4}$ of each PP session. Respiratory variables were recorded at $\mathrm{T}_{1}, \mathrm{~T}_{3}$, and $\mathrm{T}_{4}$ of each PP session. Missing data per variable are reported in Additional file 1: Table S1.

\section{Data analysis}

Significant changes in CI and global end-diastolic volume index (GEDVI) were deemed present for variations greater than $\pm 15 \%$ [19]. Patients with an increase in $\mathrm{PaO}_{2} / \mathrm{FIO}_{2} \geq 20 \mathrm{mmHg}$ or a decrease in $\mathrm{PaCO}_{2} \geq 1 \mathrm{mmHg}$ at $\mathrm{T}_{3}$ relative to $\mathrm{T}_{1}$ were classified as $\mathrm{O}_{2}$ or $\mathrm{CO}_{2}$ responders to PP, respectively [23]. Patients with both increase in $\mathrm{PaO}_{2} / \mathrm{FiO}_{2} \geq 20 \mathrm{mmHg}$ and decrease in $\mathrm{PaCO}_{2} \geq 1 \mathrm{mmHg}$ at $\mathrm{T}_{3}$ relative to $\mathrm{T}_{1}$ were classified as $\mathrm{O}_{2}$ and $\mathrm{CO}_{2}$ responders to PP. Oxygen delivery was computed as previously described [24].

\section{Statistical analysis}

Statistical analysis was performed using $\mathrm{R}$ software with packages Lme4 [25], Lmertest [26], multcomp [27], MultinomialCI [28], and OptimalCutpoints [29].

We defined the PP session as the statistical unit. Power of the study was computed using the normal approximation confidence interval method. We calculated that with a sample size of at least 196 PP sessions, the study would provide at worst a $\pm 7 \%$ precision in the $95 \%$ confidence interval $\left(\mathrm{CI}_{95 \%}\right)$ of the rate of PP sessions associated with CI improvement.

Numerical variables are expressed as mean \pm standard deviation and categorical variables as counts with corresponding percentages. $\mathrm{CI}_{95 \%}$ for multinomial proportions was computed using Sison and Glaz method [30]. Linear mixed models were used to take into account both measurement repetition during a PP session and multiple PP sessions per patient. Changes in hemodynamic variables over time were tested after adjustment for volume of fluid challenges, vasopressor and dobutamine doses to take into account therapeutic changes between time points. Multiple comparisons between groups were performed using Holm method. Diagnostic performance was assessed by computation of area under ROC curve (AUC) [31]. $\mathrm{CI}_{95 \%}$ for AUC was computed using the Delong method. The optimal cutoff points were computed by maximizing the Youden index. A $p$ value below 0.05 was chosen for statistical significance and computed using parametric bootstrapping [32].

\section{Results}

Population

A total of 191 patients fulfilled the inclusion criteria over the study period, among which 84 presented with non-inclusion criteria (Fig. 1). Characteristics of the 107 patients included in the study are reported in Table 1. Ten patients (9\%) presented with ACP during follow-up, and all patients had at least one ultrasound evaluation before the first PP session of the study, with a delay amounting to $1 \pm 2$ days. In total, $60 \mathrm{PP}$ sessions were excluded, and 197 were hence considered for analysis, whose detailed characteristics are reported in Table 2.

\section{Hemodynamic and respiratory measurements}

Actual $\mathrm{T}_{1}$ measurements were recorded $2 \pm 2 \mathrm{~h}$ before PP onset, $\mathrm{T}_{2}$ at $3 \pm 2 \mathrm{~h}$ after PP onset, $\mathrm{T}_{3}$ at $13 \pm 3 \mathrm{~h}$ after PP onset, and $\mathrm{T}_{4}$ at $2 \pm 2 \mathrm{~h}$ after return to SP.

Hemodynamic and respiratory measurements are reported in Tables 3 and 4, respectively. CI was not significantly modified during $\mathrm{PP}$ at both $\mathrm{T}_{2}$ and $\mathrm{T}_{3}$ after adjustment for fluid challenges, vasopressor and dobutamine dose, but significantly decreased after return to SP. Adjusted GEDVI increased slightly but significantly during PP and returned to baseline values at $\mathrm{T}_{4}$. Adjusted oxygen delivery decreased slightly but significantly after return to SP, without significant increase in lactate level. Response to PP was not significantly different between successive PP sessions, as we did not find any significant interaction between time points within session and successive PP sessions for all hemodynamic and respiratory variables.

\section{Early hemodynamic response to prone position at $\mathrm{T}_{\mathbf{2}}$}

Between $T_{1}$ and $T_{2}$, CI increased significantly in 42 sessions (22\% $\left.\left[\mathrm{CI}_{95 \%} 15-29 \%\right]\right)$, decreased significantly in $33\left(17 \%\left[\mathrm{CI}_{95 \%} 10-24 \%\right]\right)$, and remained stable in $119\left(61 \%\left[\mathrm{CI}_{95 \%} 55-68 \%\right]\right)$. Changes in CI between $\mathrm{T}_{1}$ and $\mathrm{T}_{2}$ (early response) and between $\mathrm{T}_{1}$ and $\mathrm{T}_{3}$ (late response) were significantly correlated $\left(R^{2}=0.42\right.$, $p<0.001$, Fig. 2a) with a concordance rate amounting to $85 \%$. Similar results were obtained with changes in GEDVI (Fig. 2b).

\section{Late hemodynamic response to prone position at $\mathrm{T}_{3}$} Between $\mathrm{T}_{1}$ and $\mathrm{T}_{3}, \mathrm{CI}$ increased significantly in 49 sessions (25\% [ $\left.\left[\mathrm{CI}_{95 \%} 18-32 \%\right]\right)$, decreased significantly in $46\left(23 \%\left[\mathrm{CI}_{95 \%} 16-31 \%\right]\right)$, and remained stable in 102 (52\% $\left.\left[\mathrm{CI}_{95 \%} 45-59 \%\right]\right)$. Patients who increased their CI during PP had significantly lower CI, GEDVI, global ejection fraction at $T_{1}$, and received significantly more fluids than patients who did not (Additional file 2: 
441 ARDS patients

250 were not treated with PP

191 ARDS patients with at least 1 PP session (439 PPS)

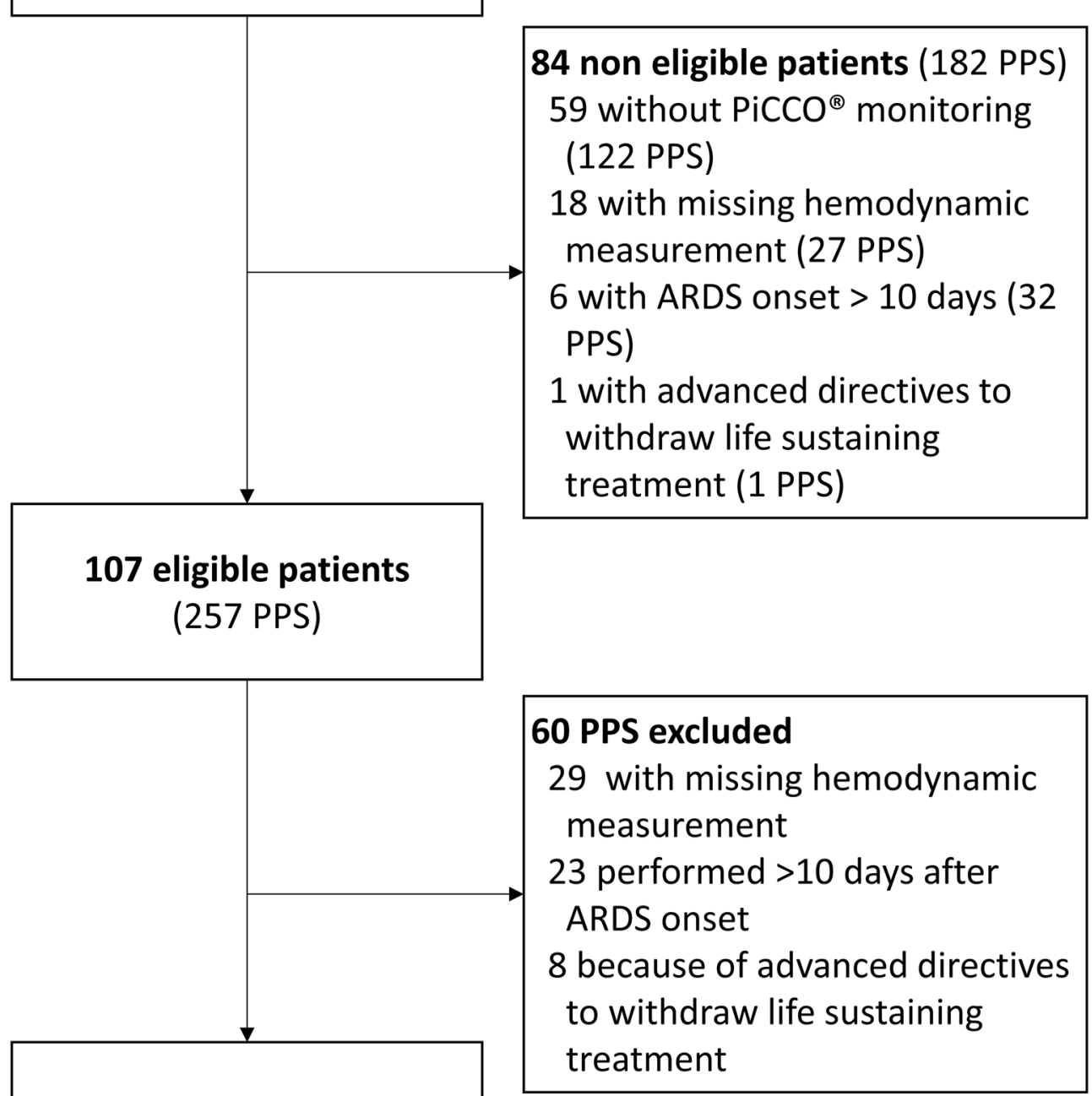

197 PPS analyzed

84 non eligible patients (182 PPS) 59 without $\mathrm{PiCCO}^{\circledR}$ monitoring (122 PPS)

8 with missing hemodynamic measurement (27 PPS)

6 with ARDS onset $>10$ days ( 32 PPS)

1 with advanced directives to s) treatment (1 PPS)

PPS excluded measurement 23 performed $>10$ days after ARDS onset 8 because of advanced directives to withdraw life sustaining treatment

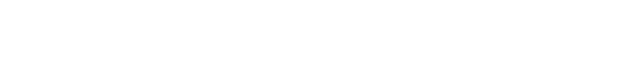

Fig. 1 Study flowchart. ARDS acute respiratory distress syndrome, PPS prone positioning session 
Table 1 Patients' characteristics

\begin{tabular}{ll}
\hline Variable & $\begin{array}{l}\text { Patients characteristics } \\
\boldsymbol{n}=107\end{array}$ \\
\hline Age (year) & $65 \pm 12(35 ; 89)$ \\
Male sex & $73(68 \%)$ \\
Body mass index $\left(\mathrm{kg} \mathrm{m}^{-2}\right)$ & $29 \pm 7(16 ; 54)$ \\
SAPS II & $62 \pm 18(32 ; 118)$ \\
Admission category & \\
Medical & $103(96 \%)$ \\
Emergent surgery & $2(2 \%)$ \\
Elective surgery & $1(1 \%)$ \\
Trauma & $1(1 \%)$ \\
ARDS severity & \\
Moderate & $30(28 \%)$ \\
Severe & $77(72 \%)$ \\
Time between ICU admission and ARDS onset & $2 \pm 4(-3 ; 27)$ \\
ARDS risk factors & \\
Pneumonia & $79(74 \%)$ \\
Aspiration & $34(32 \%)$ \\
Extra pulmonary sepsis & $10(9 \%)$ \\
None & $3(3 \%)$ \\
Acute cor pulmonale & $10(9 \%)$ \\
\hline
\end{tabular}

Values are count (percentage) or mean \pm standard deviation (extreme values) ARDS acute respiratory distress syndrome, ICU intensive care unit, SAPS II simplified acute physiology score II, SOFA sepsis-related organ failure assessment

a Total $>100 \%$ since multiple risk factors could be identified per patient

Table S2). Patients who decreased their CI between $\mathrm{T}_{1}$ and $\mathrm{T}_{3}$ had significantly higher $\mathrm{CI}$ and GEDVI at $\mathrm{T}_{1}$ and received significantly more vasopressors than patients who did not. Fluid balance during PP, oxygenation, and/ or carbon dioxide response to PP was not significantly associated with classification of $\mathrm{CI}$ response. $\mathrm{CI}$ at $\mathrm{T}_{1}$ was the variable with the best diagnostic performance to predict $\mathrm{CI}$ increase (AUC $=0.79\left[\mathrm{CI}_{95 \%} 0.73-0.86\right]$ ) and decrease $\left(\mathrm{AUC}=0.68\left[\mathrm{CI}_{95 \%}, 0.59-0.77\right]\right)$ between $\mathrm{T}_{1}$ and $\mathrm{T}_{3}$ (Additional file 3: Table S3; Additional file 4: Table S4). A CI below $2.8 \mathrm{~L} \mathrm{~min}^{-2}$ had a sensitivity of $0.69\left[\mathrm{CI}_{95 \%} 0.55-0.82\right]$ and a specificity of $0.76\left[\mathrm{CI}_{95 \%}\right.$ $0.69-0.83$ ] to predict an increase in CI greater than $15 \%$ at $\mathrm{T}_{3}$. A CI above $3.5 \mathrm{~L} \mathrm{~min} \mathrm{~m}^{-2}$ had a sensitivity of 0.63 $\left[\mathrm{CI}_{95 \%} 0.48-0.77\right]$ and a specificity of $0.70\left[\mathrm{CI}_{95 \%} 0.62-\right.$ 0.77 ] to predict a decrease in CI greater than $15 \%$ at $\mathrm{T}_{3}$.

CI response to PP was highly heterogeneous among successive sessions in the 40 patients studied repeatedly (Additional file 5: Figure S1).

Change in CI $(\Delta \mathrm{CI})$ and GEDVI $(\Delta \mathrm{GEDVI})$ between $\mathrm{T}_{1}$ and $\mathrm{T}_{3}$ were weakly correlated $\left(R^{2}=0.14, p<0.001\right.$, Additional file 6: Figure S2), while correlations were substantially higher in the following subgroups of patients based on their changes in cardiac function index between $T_{1}$ and $\mathrm{T}_{3}(\Delta \mathrm{CFI}=\Delta \mathrm{CI} / \Delta \mathrm{GEDVI})$ : patients with $\Delta \mathrm{CFI} \geq 15 \%$
Table 2 Characteristics of prone positioning sessions

\begin{tabular}{|c|c|}
\hline Variables & $\begin{array}{l}\text { Session } \\
\text { characteristics } \\
n=197\end{array}$ \\
\hline Number of PP sessions per patient & $2 \pm 2$ \\
\hline Time between ARDS onset and PP session onset (day) & $3 \pm 3$ \\
\hline Duration of PP session (h) & $16 \pm 3$ \\
\hline SOFA score & $15 \pm 4$ \\
\hline Body weight at PP session onset $(\mathrm{kg})$ & $86 \pm 19$ \\
\hline Cumulative fluid balance at PP session onset (kg) & $2.3 \pm 6.5$ \\
\hline Fluid balance during PP session $(\mathrm{kg})$ & $0.8 \pm 3.3$ \\
\hline Fluid challenge during PP session & $78(40 \%)$ \\
\hline Volume of fluid challenges during PP session (mL) & $505 \pm 1069$ \\
\hline Renal replacement therapy & $84(43 \%)$ \\
\hline Dobutamine administration & $62(31 \%)$ \\
\hline Vasopressor administration & $166(84 \%)$ \\
\hline Inhaled nitric oxide & $39(20 \%)$ \\
\hline Neuromuscular blocking agents & $182(92 \%)$ \\
\hline $\mathrm{O}_{2}$ responders to $\mathrm{PP}$ & $157(80 \%)$ \\
\hline $\mathrm{CO}_{2}$ responders to $\mathrm{PP}$ & $97(49 \%)$ \\
\hline $\mathrm{O}_{2}$ and $\mathrm{CO}_{2}$ responders to $\mathrm{PP}$ & $85(43 \%)$ \\
\hline
\end{tabular}

Values are count (percentage) or mean \pm standard deviation

$\mathrm{CO}_{2}$ responders to $\mathrm{PP}=$ patients in which $\mathrm{PaCO}_{2}$ decreases by at least $1 \mathrm{mmHg}$ between end of PP session and before PP session. $\mathrm{O}_{2}$ responders to $\mathrm{PP}=$ patients in which $\mathrm{PaO}_{2} / \mathrm{FiO}_{2}$ increases by at least $20 \mathrm{mmHg}$ between end of PP session and before PP session. $\mathrm{O}_{2}$ and $\mathrm{CO}_{2}$ responders to $\mathrm{PP}=$ patients in which $\mathrm{PaO}_{2} / \mathrm{FiO}_{2}$ increases by at least $20 \mathrm{mmHg}$ and $\mathrm{PaCO}_{2}$ decreases by at least $1 \mathrm{mmHg}$ between end of PP session and before PP session

$P P$ prone position, SOFA sepsis-related organ failure assessment

(i.e., with $\mathrm{CI}$ increase not fully explained by an increase in GEDVI), patients with $-15 \%<\Delta \mathrm{CFI}<15 \%$ (i.e., with $\mathrm{CI}$ changes explained by changes in GEDVI or no variation in both GEDVI and CI), and patients with $\triangle \mathrm{CFI} \leq-15 \%$ (i.e., with CI decrease not fully explained by a decrease in GEDVI).

Changes in CI and GEDVI beyond significant thresholds between $\mathrm{T}_{1}$ and $\mathrm{T}_{3}$, or $\mathrm{T}_{3}$ and $\mathrm{T}_{4}$, were used to classify sessions into nine categories (Fig. 3), in an attempt to identify groups with $\mathrm{CI}$ variations related or unrelated to changes in GEDVI. CI increase between $\mathrm{T}_{1}$ and $\mathrm{T}_{3}$ was associated with GEDVI increase in $11 \%$ of the sessions (mainly during sessions without concomitant fluid challenge), with stable GEDVI in 13\%, and with GEDVI decrease in $1 \%$. Virtually all PP sessions performed on patients with ACP were associated with no change or an increase in CI between $T_{1}$ and $T_{3}$ (Fig. 3). CI decrease between $T_{1}$ and $T_{3}$ was mainly associated with stable GEDVI occurring in $16 \%$ of the sessions.

\section{Hemodynamic response during the shift from prone to supine position}

CI decreased between $\mathrm{T}_{3}$ and $\mathrm{T}_{4}$ in $27 \%$ of the sessions and was associated with a decrease in GEDVI in $10 \%$ of 
Table 3 Hemodynamic parameters during prone positioning session

\begin{tabular}{|c|c|c|c|c|}
\hline Variables & $\mathrm{T}_{1}$ & $\mathrm{~T}_{2}$ & $\mathrm{~T}_{3}$ & $\mathrm{~T}_{4}$ \\
\hline $\mathrm{HR}\left(\mathrm{min}^{-1}\right)$ & $98 \pm 23$ & $99 \pm 20^{a}$ & $96 \pm 20$ & $95 \pm 21$ \\
\hline MAP $(\mathrm{mmHg})$ & $76 \pm 10$ & $79 \pm 12^{c}$ & $77 \pm 12$ & $78 \pm 14$ \\
\hline $\mathrm{CVP}\left(\mathrm{cm} \mathrm{H}_{2} \mathrm{O}\right)$ & $13 \pm 5$ & $14 \pm 5^{c}$ & $13 \pm 5$ & $14 \pm 5$ \\
\hline $\mathrm{Cl}\left(\mathrm{L} \min \mathrm{m}^{-2}\right)$ & $3.5 \pm 1.3^{\mathrm{a}}$ & $3.4 \pm 1.2^{\mathrm{a}}$ & $3.4 \pm 1.1^{\mathrm{a}}$ & $3.2 \pm 1.1$ \\
\hline GEF (\%) & $21 \pm 7$ & $20 \pm 7^{c}$ & $21 \pm 8$ & $21 \pm 7$ \\
\hline EVLWI (mL kg ${ }^{-1}$ PBW) & $13.8 \pm 4.4$ & $14.2 \pm 4.7^{\mathrm{a}}$ & $13.7 \pm 4.7$ & $13.1 \pm 4.0$ \\
\hline PVPI & $2.6 \pm 1.0^{b}$ & $2.5 \pm 0.9$ & $2.4 \pm 0.9$ & $2.5 \pm 0.9$ \\
\hline GEDVI $\left(m L m^{-2}\right)$ & $719 \pm 193$ & $738 \pm 185^{a, c}$ & $757 \pm 209^{a, c}$ & $714 \pm 200$ \\
\hline $\mathrm{CFI}\left(\mathrm{min}^{-1}\right)$ & $5.0 \pm 1.9$ & $4.8 \pm 1.8^{c}$ & $4.8 \pm 1.8^{c}$ & $4.7 \pm 1.8^{c}$ \\
\hline PTV $(m L)$ & $1163 \pm 362^{\mathrm{a}}$ & $1189 \pm 359^{\mathrm{a}}$ & $1173 \pm 354^{\mathrm{a}}$ & $1116 \pm 327$ \\
\hline ITTV $(\mathrm{mL})$ & $2539 \pm 653$ & $2602 \pm 638^{\mathrm{a}, \mathrm{c}}$ & $2619 \pm 664^{\mathrm{a}, \mathrm{c}}$ & $2482 \pm 655$ \\
\hline $\mathrm{DO}_{2}\left(\mathrm{~mL} \min \mathrm{m}^{-2}\right)$ & $416 \pm 145$ & NA & $414 \pm 139$ & $387 \pm 126^{\mathrm{b}, \mathrm{c}}$ \\
\hline Vasopressor dose $\left(\mu \mathrm{g} \mathrm{kg} \mathrm{min}{ }^{-1}\right)$ & $0.92 \pm 1.66$ & $0.92 \pm 2.04$ & $0.84 \pm 1.67^{c}$ & $0.88 \pm 1.76^{c}$ \\
\hline Dobutamine dose $e^{* *}\left(\mu \mathrm{g} \mathrm{kg} \mathrm{min}{ }^{-1}\right)$ & $2.6 \pm 6.0$ & $2.6 \pm 5.8$ & $2.8 \pm 6.1$ & $3.0 \pm 6.2$ \\
\hline $\begin{array}{l}\text { Volume of fluid challenge since preceding time } \\
\text { point }^{* * *}(\mathrm{~mL})\end{array}$ & NA & $158 \pm 519$ & $224 \pm 566$ & $123 \pm 340$ \\
\hline
\end{tabular}

Values are mean \pm standard deviation. All statistical tests are performed after adjustment for volume of fluid challenges since preceding time point, vasopressor and dobutamine dose unless specifically stated

$\mathrm{Cl}$, cardiac index; $\mathrm{CFI}$, cardiac function index; $\mathrm{CVP}$, central venous pressure; $\mathrm{DO}_{2}$, oxygen delivery; EVLWI, extravascular lung water index; GEDVI, global end-diastolic volume index; GEF, global ejection fraction; HR, heart rate; ITTV, intrathoracic thermal volume; MAP, mean arterial pressure; NA, not available; PBW, predicted body weight; PTV, pulmonary thermal volume; PVPI, pulmonary vascular permeability index; $T_{1}$, before prone position, $T_{2}$, beginning of prone position session; $T_{3}$, end of prone position session; $\mathrm{T}_{4}$, after prone position session

${ }^{\mathrm{a}} p<0.05$ versus $\mathrm{T}_{4} ;{ }^{\mathrm{b}} p<0.05$ versus $\mathrm{T}_{3} ;{ }^{c} p<0.05$ versus $\mathrm{T}_{1}$

* Adjustment for volume of fluid challenges since preceding time point and dobutamine dose only; ${ }^{* *}$ adjustment for volume of fluid challenges since preceding time point and vasopressor dose only; ${ }^{* * *}$ not tested for statistical significance

Table 4 Respiratory parameters during prone positioning session

\begin{tabular}{|c|c|c|c|}
\hline Variables & $\mathrm{T}_{1}$ & $T_{3}$ & $\mathrm{~T}_{4}$ \\
\hline VT (mL kg-1 PBW) & $6.2 \pm 0.7$ & $6.2 \pm 0.8$ & $6.1 \pm 0.8$ \\
\hline $\operatorname{RR}\left(\min ^{-1}\right)$ & $29 \pm 5$ & $29 \pm 5$ & $29 \pm 5$ \\
\hline |:E ratio (\%) & $42 \pm 11$ & $40 \pm 9$ & $39 \pm 9$ \\
\hline PEEP $\left(\mathrm{cm} \mathrm{H}_{2} \mathrm{O}\right)$ & $10 \pm 3^{a, b}$ & $9 \pm 3$ & $9 \pm 3$ \\
\hline PEEPtot $\left(\mathrm{cm} \mathrm{H}_{2} \mathrm{O}\right)$ & $11 \pm 2$ & $10 \pm 3$ & $10 \pm 3$ \\
\hline Pplat $\left(\mathrm{cm} \mathrm{H}_{2} \mathrm{O}\right)$ & $23 \pm 4$ & $22 \pm 5^{c}$ & $22 \pm 4^{c}$ \\
\hline$\Delta p\left(\mathrm{~cm} \mathrm{H}_{2} \mathrm{O}\right)$ & $12 \pm 4$ & $11 \pm 4$ & $11 \pm 3$ \\
\hline $\mathrm{pH}$ & $7.35 \pm 0.10$ & $7.38 \pm 0.09^{\mathrm{a}, \mathrm{c}}$ & $7.37 \pm 0.09$ \\
\hline $\mathrm{PaCO}_{2}(\mathrm{mmHg})$ & $45 \pm 10$ & $43 \pm 11$ & $44 \pm 10$ \\
\hline $\mathrm{PaO}_{2} / \mathrm{FiO}_{2}$ & $112 \pm 28$ & $179 \pm 62^{\mathrm{a}, \mathrm{c}}$ & $153 \pm 60^{c}$ \\
\hline Lactate (mmol L ${ }^{-1}$ ) & $3.6 \pm 3.2$ & $3.3 \pm 3.0$ & $3.2 \pm 3.0$ \\
\hline Hemoglobin $\left(\mathrm{g} \mathrm{L}^{-1}\right)$ & $101 \pm 22$ & $98 \pm 21^{c}$ & $98 \pm 20^{c}$ \\
\hline
\end{tabular}

Values are mean \pm standard deviation

$\Delta p$, driving pressure; $\mathrm{FiO}_{2}$, inspired oxygen fraction; I:E ratio, inspiratory-toexpiratory time ratio; $\mathrm{PaCO}_{2}$, partial pressure of arterial carbon dioxide; $\mathrm{PaO}_{2}$, partial pressure of arterial oxygen; PBW, predicted body weight; PEEP, external PEEP; PEEPtot, total PEEP of the respiratory system; Pplat, plateau pressure of the respiratory system; $\mathrm{RR}$, respiratory rate; $\mathrm{T}_{1}$, before prone position, $\mathrm{T}_{3}$, end of prone position session; $\mathrm{T}_{4}$, after prone position session; $\mathrm{VT}$, tidal volume

${ }^{\text {a }} p<0.05$ versus $\mathrm{T}_{4} ;{ }^{\mathrm{b}} p<0.05$ versus $\mathrm{T}_{3} ;{ }^{\mathrm{c}} p<0.05$ versus $\mathrm{T}_{1}$ the sessions and with a stable GEDVI in $17 \%$ of the sessions (Fig. 4).

Change in CI between $T_{1}$ and $T_{3}$ was not correlated with change in CI between $\mathrm{T}_{3}$ and $\mathrm{T}_{4}$, while change in GEDVI between $T_{1}$ and $T_{3}$ was negatively correlated with change in GEDVI between $\mathrm{T}_{3}$ and $\mathrm{T}_{4}$ (Additional file 7: Figure S3).

\section{Discussion}

The main findings of the study are the following: (1) Early and late hemodynamic response to PP are strongly related; (2) CI significantly increases at the end of $25 \%$ of PP sessions; (3) PP is associated with a slight yet sustained increase in GEDVI, reversible after return in SP, unrelated to fluid administration; (4) return to SP is associated with a small but significant decrease in $\mathrm{CI}$ and oxygen delivery; (5) PP may improve cardiovascular status by increasing cardiac preload and hence $\mathrm{CI}$ in patients with preload responsiveness.

\section{Effect of prone position on $\mathrm{Cl}$}

The study results are in line with previous smaller studies showing the lack of significant impact of the shift from SP to PP on CI in unselected ARDS patients 

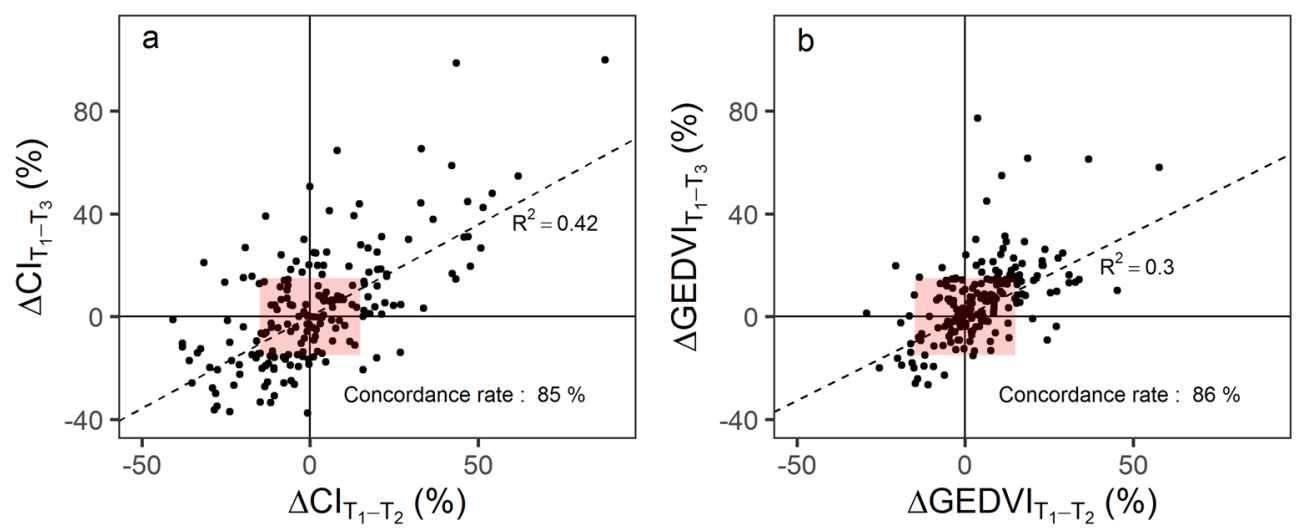

Fig. 2 Early versus late changes in $\mathrm{Cl}$ (a) and GEDVI (b) during prone position. Symbols are individual values for each prone position session. Broken lines are regression lines performed on the whole dataset with corresponding $R^{2}$. Concordance rate is the percentage of data points falling into one of the two quadrants of agreement (i.e., upper right and lower left quadrants in which hemodynamic variations between $T_{1}$ and $T_{2}$ and between $T_{1}$ and $T_{3}$ have the same directional changes). Red rectangles are exclusion zones for computation of concordance rate, excluding data points with

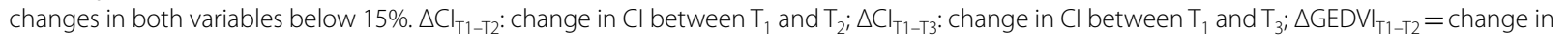
GEDVI between $T_{1}$ and $T_{2} ; \Delta G E D V I_{T 1-T 3}=$ change in GEDVI between $T_{1}$ and $T_{3}$
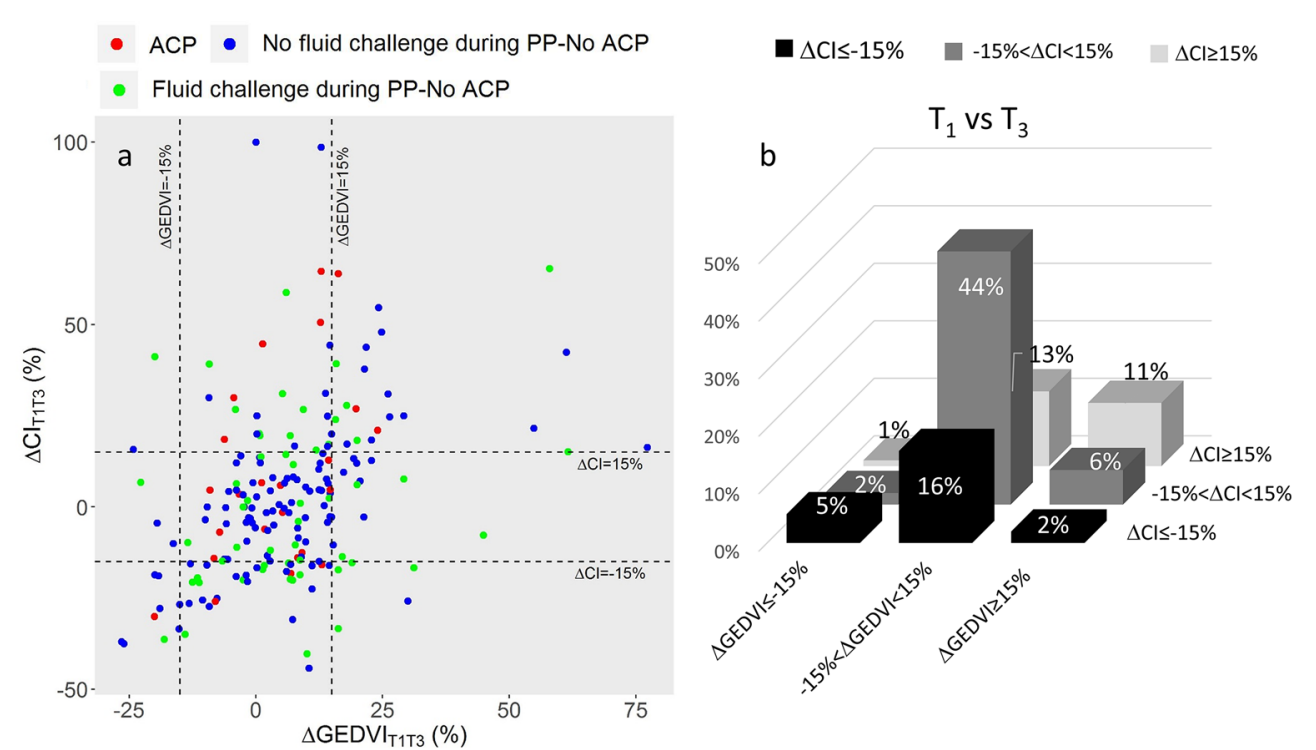

Fig. 3 Hemodynamic pattern as a function of $\triangle C l$ and $\triangle G E D V I$ between $T_{1}$ and $T_{3}$. a Symbols are individual values for each prone position session. Broken lines are threshold values for significant changes in $\mathrm{Cl}$ (+or $-15 \%)$ and GEDVI (+or $-15 \%)$. Red dots refer to patients with ACP. Blue dots refer to patients without $A C P$ and without fluid challenge between $T_{1}$ and $T_{3}$. Green dots refer to patients without $A C P$ and with any fluid challenge between $\mathrm{T}_{1}$ and $\mathrm{T}_{3}$. $\mathbf{b}$ Bars are percentage of patients falling in each category. $\mathrm{Cl}$, cardiac index; GEDVI, global end-diastolic volume index; ACP, acute cor pulmonale; $\triangle \mathrm{Cl}$, change in $\mathrm{Cl} ; \triangle \mathrm{GEDVI}$, change in GEDVI; $\mathrm{PP}$, prone position; $\mathrm{T}_{1}$, before prone position; $\mathrm{T}_{3}$, end of prone position session

[4-10]. Still, $25 \%$ of the PP sessions were associated with a significant increase in $\mathrm{CI}$ at $\mathrm{T}_{3}$ compared to baseline, of which approximately half were related to an increase in GEDVI (and presumably an increase in cardiac preload). Of note, most of these patients increased their GEDVI without receiving any fluid challenge.
The remaining half displayed no detectable change in GEDVI, suggesting an improvement in CI unrelated to cardiac preload. It may be speculated that this latter group of patients might encompass patients with various degrees of pulmonary vascular system dysfunction, benefiting from the unloading of their right ventricle in response to PP [12]. Of note, the rate of PP sessions 


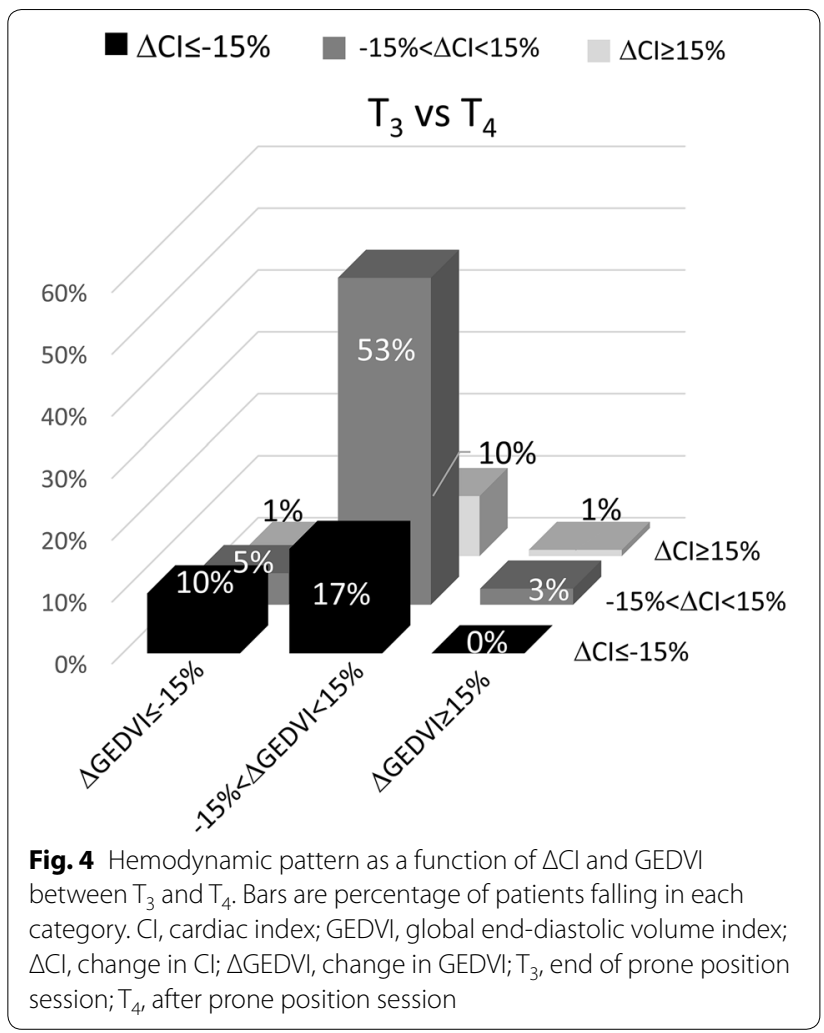

associated with an increase in CI related to cardiac preload increase at $T_{3}$ is substantially lower in the present study than in Jozwiak et al. [13]. Besides differences in case mix, timing of measurements, and PEEP management, a difference in the starting position (strict supine in the present study vs. $45^{\circ}$ semi-recumbent) may partly explain this discrepancy. Oppositely, 23\% of the PP sessions were associated with a significant decrease in $\mathrm{CI}$ at $\mathrm{T}_{3}$ compared to baseline, the majority of which without detectable change in GEDVI. The significantly greater CI, GEDVI, and vasopressor dose at baseline in this subgroup of patients suggest that the decrease in CI during PP may be related to resolution of an hyperdynamic state during the PP session. Finally, the high concordance rate between early and late cardiac index changes suggests that hemodynamic response to PP is persistent throughout the whole PP session.

Unlike previous smaller studies $[4,6,11]$, the present study identified a small but significant decrease in $\mathrm{CI}$ and oxygen delivery during the shift from PP to SP. Apart from differences in case mix, ventilatory settings, or timing of measurement, it is likely that previous studies were strongly underpowered to detect this effect. Our data suggest that this decrease is related to a decrease in preload in approximately $1 / 3$ of the sessions, suggesting reversal of the PP-related preload improvement effect identified by Jozwiak et al. [13].

\section{Effect of prone position on GEDVI}

We observed a slight but significant increase in GEDVI at the end of the PP session, reversible after return to the SP, in line with a previous smaller study [33]. Since PP modifies regional ventilation-perfusion ratios [34], it has been speculated that this slight increase in GEDVI might be related to an increase in pulmonary thermal volume in PP. The lack of significant difference regarding this parameter between $T_{1}, T_{2}$ and $T_{3}$ does not support this hypothesis, along with the fact that most of the PP sessions with significant increase in GEDVI between $T_{1}$ and $\mathrm{T}_{3}$ were associated with an increase in CI. This suggests that changes in GEDVI during the PP session remain a reliable indicator of changes in preload.

It might be questioned whether the slight increase in GEDVI related to the shift from supine to PP is associated with a meaningful increase in cardiac preload. Since this increase is of similar magnitude than that provided by a $500-\mathrm{mL}$ fluid challenge $[35,36]$, it suggests that the observed change in cardiac preload related to PP is clinically relevant. Furthermore, our study confirms the positive effect of PP on cardiac preload previously shown in a smaller study within 20 min after the postural change [13] and extends this finding up to the end of longer PP sessions [1].

\section{Strengths and limits}

Some limitations of the present study should be acknowledged. First, the retrospective feature of the study explains the heterogeneity between patients regarding assessment time points and the high rate of missing values for some variables. Second, the present study selected a subpopulation of ARDS patients with acute circulatory failure requiring $\mathrm{PiCCO}^{\circledR}$ monitoring, making a selection bias uncontrolled for. Third, the observational design does not allow to control for the effect of time. Fourth, some important variables are lacking (pulmonary artery pressure, comprehensive evaluation of right ventricle function, assessment of preload reserve status, etc.), hindering interpretation of hemodynamic data. Five, co-interventions (such as fluid loading, change in vasopressor dose) during study could have interfered with PP effect on hemodynamics, although these confounders were accounted for in the statistical analysis. Sixth, a $15 \%$ conservative threshold was used to detect significant changes in CI and GEDVI, since the least significant change detectable by thermodilution is around $12 \%$ when three boluses are used for $\mathrm{PiCCO}^{\circledR}$ calibration [19], thereby limiting the potential of this technique for detecting hemodynamic changes. Seven, the rate of 
patients with ACP was low in the present study (9\%), as compared to $22 \%$ in a recent multicenter study [14], and may be partly explained by the lack of systematic daily ultrasound evaluation in the present study, but may be also related to higher tidal volumes $\left(6.2 \mathrm{vs.} 6.8 \mathrm{~mL} \mathrm{~kg}^{-1}\right)$ and driving pressures $\left(12\right.$ vs. $\left.16 \mathrm{~cm} \mathrm{H}_{2} \mathrm{O}\right)$ in the latter, in addition to a lower use of PP (100\% vs. $29 \%)$.

Nevertheless, the number of studied PP sessions outranks by almost one order of magnitude previous studies on the effect of PP on CI. This substantial size allowed to compute rates of $\mathrm{CI}$ response to $\mathrm{PP}$ with relatively narrow confidence intervals and to perform multivariate analysis of factors associated with CI variations, allowing control of confounding variables.

\section{Clinical implications}

The present study identified a beneficial effect of PP on CI in $25 \%$ of the sessions, especially in patients with lower CI before PP, associated with an increase in cardiac preload. This suggests that hemodynamic instability should not be an obstacle to PP. Since return to SP may be associated with a decrease in CI in approximately a quarter of the PP sessions, serial evaluations of $\mathrm{CI}$ and fluid responsiveness may be recommended during this period.

\section{Conclusions}

Prone position is associated with an increase in CI in $18 \%$ to $32 \%$ of the PP sessions and a sustained increase in GEDVI, both reversible after return to SP. PP may improve $\mathrm{CI}$ by increasing cardiac preload in patients with preload responsiveness. Return from PP to SP is associated with a slight hemodynamic impairment, at least partly related to decreased cardiac preload.

\section{Additional files}

Additional file 1. Missing values per variable.

Additional file 2. Univariate analysis of cardiac index response to prone position.

Additional file 3. Diagnostic performance of variables assessed at $T_{1}$ to predict an increase in $\mathrm{Cl}$ greater than $15 \%$ between $\mathrm{T}_{1}$ and $\mathrm{T}_{3}$.

Additional file 4. Diagnostic performance of variables assessed at $T_{1}$ to predict a decrease in $\mathrm{Cl}$ greater than $15 \%$ between $\mathrm{T}_{1}$ and $\mathrm{T}_{3}$.

Additional file 5. Cardiac index response to prone position in the 40 patients with multiple prone position sessions.

Additional file 6 . Correlation between $\mathrm{Cl}$ and GEDVI changes between $\mathrm{T}_{1}$ and $\mathrm{T}_{3}$.

Additional file 7. Change in cardiac index and global end-diastolic volume between $T_{1}$ and $T_{3}$ and between $T_{3}$ and $T_{4}$.

Additional file 8. Dataset.
Abbreviations

ACP: acute cor pulmonale; ARDS: acute respiratory distress syndrome; AUC: area under ROC curve; $\mathrm{Cl}$ : cardiac index; $\mathrm{Cl}_{95 \%}$ : $95 \%$ confidence interval; GEDVI: global end-diastolic volume index; ICU: intensive care unit; PEEP: positive endexpiratory pressure; PP: prone position; SP: supine position.

\section{Authors' contributions}

MR made substantial contributions to data acquisition, study analysis, and interpretation of data; AND drafted the manuscript, AND approved the version to be published; AND agreed to be accountable for all aspects of the work in ensuring that questions related to the accuracy or integrity of any part of the work are appropriately investigated and resolved. LB made substantial contributions to study analysis, and interpretation of data; AND revised the manuscript for important intellectual content; AND approved the version to be published. HY made substantial contributions to study analysis and interpretation of data; AND revised the manuscript for important intellectual content; AND approved the version to be published. ZR made substantial contributions to study analysis and interpretation of data; AND revised the manuscript for important intellectual content; AND approved the version to be published. ALD made substantial contributions to study analysis and interpretation of data; AND revised the manuscript for important intellectual content; AND approved the version to be published. FL made substantial contributions to study analysis and interpretation of data; AND revised the manuscript for important intellectual content; AND approved the version to be published. SPR made substantial contributions to study analysis and interpretation of data; AND revised the manuscript for important intellectual content; AND approved the version to be published. CG made substantial contributions to study design, data acquisition, study analysis, and interpretation of data; AND revised the manuscript for important intellectual content; AND approved the version to be published. JCR made substantial contributions to study design, study analysis, and interpretation of data; AND drafted the manuscript; AND approved the version to be published; AND agreed to be accountable for all aspects of the work in ensuring that questions related to the accuracy or integrity of any part of the work are appropriately investigated and resolved. All authors read and approved the final manuscript.

\section{Author details}

${ }^{1}$ Service de Réanimation Médicale, Hôpital De La Croix Rousse, Hospices Civils de Lyon, 103 Grande Rue de la Croix Rousse, 69004 Lyon, France. ${ }^{2}$ Université de Lyon, Université LYON I, Lyon, France. ${ }^{3}$ IMRB, INSERM 955Eq13, Créteil, France. ${ }^{4}$ CREATIS INSERM 1044 CNRS 5220, Villeurbanne, France.

\section{Acknowledgements}

Not applicable.

Competing interests

The authors declare that they have no competing interests.

\section{Availability of data and materials}

All data generated or analyzed during this study are included in this published article and its supplementary information files (see Additional file 8).

\section{Consent for publication}

Not applicable.

\section{Ethics approval and consent to participate}

The study protocol was approved by an Ethics Committee (CPP Sud-Est II, IRB 9118), which waived the requirement for informed consent.

\section{Funding}

None.

\section{Publisher's Note}

Springer Nature remains neutral with regard to jurisdictional claims in published maps and institutional affiliations.

Received: 18 July 2018 Accepted: 30 November 2018

Published online: 07 December 2018 


\section{References}

1. Guerin C, Reignier J, Richard J-C, Beuret P, Gacouin A, Boulain T, et al. Prone positioning in severe acute respiratory distress syndrome. N Engl J Med. 2013;368:2159-68

2. Guérin C, Beuret P, Constantin JM, Bellani G, Garcia-Olivares P, Roca O, et al. A prospective international observational prevalence study on prone positioning of ARDS patients: the APRONET (ARDS Prone Position Network) study. Intensive Care Med. 2018;44:22-37.

3. Fridrich $P$, Krafft $P$, Hochleuthner $H$, Mauritz W. The effects of long-term prone positioning in patients with trauma-induced adult respiratory distress syndrome. Anesth Analg. 1996;83:1206-11.

4. Jolliet P, Bulpa P, Chevrolet JC. Effects of the prone position on gas exchange and hemodynamics in severe acute respiratory distress syndrome. Crit Care Med. 1998;26:1977-85.

5. Germann P, Pöschl G, Leitner C, Urak G, Ullrich R, Faryniak B, et al. Additive effect of nitric oxide inhalation on the oxygenation benefit of the prone position in the adult respiratory distress syndrome. Anesthesiology. 1998:89:1401-6.

6. Pelosi P, Tubiolo D, Mascheroni D, Vicardi P, Crotti S, Valenza F, et al. Effects of the prone position on respiratory mechanics and gas exchange during acute lung injury. Am J Respir Crit Care Med. 1998;157:387-93.

7. Kiefer P, Morin A, Putzke C, Wiedeck H, Georgieff M, Radermacher P. Influence of prone position on gastric mucosal-arterial $\mathrm{PCO}_{2}$ gradients. Intensive Care Med. 2001;27:1227-30.

8. Lee DL, Chiang HT, Lin SL, Ger LP, Kun MH, Huang YC. Prone-position ventilation induces sustained improvement in oxygenation in patients with acute respiratory distress syndrome who have a large shunt. Crit Care Med. 2002;30:1446-52.

9. McAuley DF, Giles S, Fichter H, Perkins GD, Gao F. What is the optimal duration of ventilation in the prone position in acute lung injury and acute respiratory distress syndrome? Intensive Care Med. 2002;28:414-8.

10. Gainnier M, Michelet P, Thirion X, Arnal JM, Sainty JM, Papazian L. Prone position and positive end-expiratory pressure in acute respiratory distress syndrome. Crit Care Med. 2003;31:2719-26.

11. Matejovic M, Rokyta R, Radermacher P, Krouzecky A, Sramek V, Novak I. Effect of prone position on hepato-splanchnic hemodynamics in acute lung injury. Intensive Care Med. 2002;28:1750-5.

12. Vieillard-Baron A, Charron C, Caille V, Belliard G, Page B, Jardin F. Prone positioning unloads the right ventricle in severe ARDS. Chest. 2007:132:1440-6.

13. Jozwiak M, Teboul J-L, Anguel N, Persichini R, Silva S, Chemla D, et al Beneficial hemodynamic effects of prone positioning in patients with acute respiratory distress syndrome. Am J Respir Crit Care Med. 2013;188:1428-33.

14. Mekontso Dessap A, Boissier F, Charron C, Bégot E, Repessé X, Legras $A$, et al. Acute cor pulmonale during protective ventilation for acute respiratory distress syndrome: prevalence, predictors, and clinical impact. Intensive Care Med. 2016:42:862-70

15. ARDS Definition Task Force, Ranieri VM, Rubenfeld GD, Thompson BT, Ferguson ND, Caldwell E, et al. Acute respiratory distress syndrome: the Berlin definition. JAMA. 2012;307:2526-33.

16. Acute Respiratory Distress Syndrome Network. Ventilation with lower tidal volumes as compared with traditional tidal volumes for acute lung injury and the acute respiratory distress syndrome. N Engl J Med. 2000;342:1301-8.

17. Papazian L, Forel JM, Gacouin A, Penot-Ragon C, Perrin G, Loundou A, et al. Neuromuscular blockers in early acute respiratory distress syndrome. N Engl J Med. 2010;363:1107-16.

18. Cecconi M, De Backer D, Antonelli M, Beale R, Bakker J, Hofer C, et al. Consensus on circulatory shock and hemodynamic monitoring. Task force of the European Society of Intensive Care Medicine. Intensive Care Med. 2014;40:1795-815.

19. Monnet X, Persichini R, Ktari M, Jozwiak M, Richard C, Teboul J-L. Precision of the transpulmonary thermodilution measurements. Crit Care. 2011;15:R204.

20. Huber W, Kraski T, Haller B, Mair S, Saugel B, Beitz A, et al. Room-temperature vs iced saline indicator injection for transpulmonary thermodilution. J Crit Care. 2014;29:1133.e7-14.

21. Le Gall JR, Lemeshow S, Saulnier F. A new Simplified Acute Physiology Score (SAPS II) based on a European/North American multicenter study. JAMA. 1993;270:2957-63.

22. Vincent JL, Moreno R, Takala J, Willatts S, De Mendonca A, Bruining $\mathrm{H}$, et al. The SOFA (Sepsis-related Organ Failure Assessment) score to describe organ dysfunction/failure. On behalf of the Working Group on Sepsis-Related Problems of the European Society of Intensive Care Medicine. Intensive Care Med. 1996:22:707-10.

23. Gattinoni L, Vagginelli F, Carlesso E, Taccone P, Conte V, Chiumello D, et al. Decrease in $\mathrm{PaCO}_{2}$ with prone position is predictive of improved outcome in acute respiratory distress syndrome. Crit Care Med. 2003;31:2727-33.

24. Bihari D, Smithies M, Gimson A, Tinker J. The effects of vasodilation with prostacyclin on oxygen delivery and uptake in critically ill patients. N Engl J Med. 1987;317:397-403.

25. Bates D, Maechler M, Bolker B, Walker S. Fitting linear mixed-effects models using Ime4. J Stat Softw. 2015;67:1-48.

26. Kuznetsova A, Brockhoff PB, Christensen RHB. LmerTest: tests in linear mixed effects models. 2016. http://CRAN.R-project.org/package=ImerT est. Accessed 5 Dec 2018

27. Hothorn T, Bretz F, Westfall P. Simultaneous inference in general parametric models. Biom J. 2008;50:346-63.

28. Villacorta PJ. MultinomialCl: simultaneous confidence intervals for multinomial proportions according to the method by Sison and Glaz. 2012. https://CRAN.R-project.org/package=MultinomialCl. Accessed 5 Dec 2018.

29. Lopez-Raton M, Rodriguez-Alvarez MX, Cadarso-Suárez C, Gude-Sampedro F. OptimalCutpoints: an R package for selecting optimal cutpoints in diagnostic tests. J Stat Softw. 2014;61:1-36.

30. Sison CP, Glaz J. Simultaneous confidence intervals and sample size determination for multinomial proportions. J Am Stat Assoc. 1995;90:366-9.

31. Robin X, Turck N, Hainard A, Tiberti N, Lisacek F, Sanchez J-C, et al. pROC an open-source package for $\mathrm{R}$ and $\mathrm{S}+$ to analyze and compare $\mathrm{ROC}$ curves. BMC Bioinform. 2011:12:77.

32. Luke SG. Evaluating significance in linear mixed-effects models in R. Behav Res Methods. 2017:49:1494-502.

33. Brücken U, Grensemann J, Wappler F, Sakka SG. Influence of prone positioning on the measurement of transpulmonary thermodilution-derived variables in critically ill patients. Acta Anaesthesiol Scand. 2011;55:1061-7.

34. Richard JC, Bregeon F, Costes N, Bars DL, Tourvieille C, Lavenne F, et al. Effects of prone position and positive end-expiratory pressure on lung perfusion and ventilation. Crit Care Med. 2008;36:2373-80.

35. Michard F, Alaya S, Zarka V, Bahloul M, Richard C, Teboul JL. Global enddiastolic volume as an indicator of cardiac preload in patients with septic shock. Chest. 2003;124:1900-8.

36. Yonis H, Bitker L, Aublanc M, Perinel Ragey S, Riad Z, Lissonde F, et al. Change in cardiac output during Trendelenburg maneuver is a reliable predictor of fluid responsiveness in patients with acute respiratory distress syndrome in the prone position under protective ventilation. Crit Care. 2017:21:295. 